\title{
Migraine With Aura
}

National Cancer Institute

\section{Source}

National Cancer Institute. Migraine With Aura. NCI Thesaurus. Code C117005.

A migraine disorder characterized by episodes that are preceded by focal neurological symptoms. 